\title{
Mukherjee's Equation: An Equation to Calculate GFR of an Obese Asian
}

Dear Editor,

Glomerular Filtration Rate [GFR] is an essential value to understand the condition of two kidneys. ${ }^{1}$ Currently we are using different formulas to calculate it. One of the formulae is 1973s Cockcroft-Gault formula. ${ }^{2}$ The formula is:

$$
\mathrm{C}_{\mathrm{Cr}}=\{[140-\text {-age }] \times \mathrm{wt}\} / \mathrm{S} . \mathrm{Cr} \times 72
$$

Wherein

- $\mathrm{CCr}$ (creatinine clearance) $=\mathrm{mL} /$ minute, this reflects the GFR

- $\quad$ Age = years

- $\quad$ Weight $=\mathrm{kg}$

- $\mathrm{SCr}$ (serum creatinine) $=\mathrm{mg} / \mathrm{dL}$

Currently the most used formula is 2009 CKD-EPI creatinine equation ${ }^{3}$ which has parameters like $\mathrm{SCr}$, Age, Gender, Race.

Now, I have studied and realized that we are missing with an important factor, that is height which is a very important demographic factor. Several studies have shown that BMI is inversely proportional to GFR. ${ }^{4}$ So, after calculating I am proposing an equation which has height as a measuring factor. This equation will be called Mukherjee's equation. The equation is:

$$
\text { GFR }=[2100-\text { age }] /[0.72 \times \text { S.cr } \times \text { BMI }]
$$

Wherein:

- $\quad$ BMI=Weight in $\mathrm{Kg} /$ Hight in $\mathrm{m}^{2}$

- $\quad$ Age in years

- $\quad$ S.Cr in $\mathrm{mg} / \mathrm{dl}$

Points to be noted:

1. This formula is for Asian patients

2. Age is more than 18 years
3. Only for obese patients, BMI $>30$

4. For female, the value will be multiplied by 0.8

I am proposing this equation and, in my calculation, I have found some differences with the conventional one. I believe this equation will give more precise result than the conventional one. Through this equation, I have tried to create a bridge between Cockcroft and 2009 CKD-EPI. Although, a clinical trial is needed to validate this equation. Through this article, I am first proposing my equation, Mukherjee's Equation in front of the scientific world.

\section{REFERENCES:}

1. Medline Plus. Glomerular Filtration Rate, US National Library of Medicine (Online Article). Available from: https://medlineplus.gov/ency/article/007305.htm [Last Accessed on $15^{\text {th }}$ August, 2021]

2. National Kidney Foundation. Cockroft Gault Formula. (Online Article). Available from: https://www.kidney.org/professionals/kdoqi/gfr calc ulatorcoc. [Last Accessed on $25^{\text {th }}$ June, 2021]

3. Da Vita. Glomerular Calculator. (Online Article). Available from: https:/www.davita.com/tools/gfrcalculator. [Last Accessed on 25 ${ }^{\text {th }}$ June, 2021]

4. Kawamoto R, Kohara K, Tabara Y, Miki T, Ohtsuka N, Kusunoki T, Yorimitsu N. An association between body mass index and estimated glomerular filtration rate. Hypertens Res. 2008;31(8):1559-64. doi: https://doi.org/10.1291/hypres.31.1559. 
Cite this article as:

Mukherjee D. Mukherjee's Equation: An Equation to Calculate GFR of an Obese Asian. Int

Healthc Res J. 2021;5(7):LE1-LE2. https://doi.org/10.26440/IHRJ/0507.10437

e-mail id for correspondence: dattatreyamukherjee4u[at]outlook[dot]com 